\title{
ÁMBITOS Y ESCENARIOS DE PARTICIPACIÓN POLÍTICA JUVENIL EN MEDELLÍN ${ }^{*}$
}

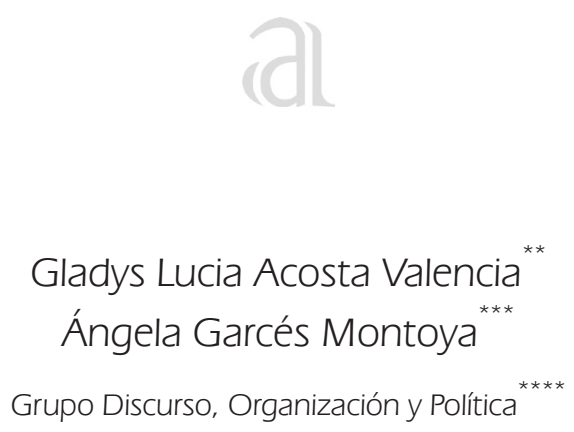

Recibido: 24 de marzo de 2010. Aceptado: 28 de abril de 2010.

\begin{abstract}
RESUMEN
En el marco de la investigación "Prácticas de participación política juvenil desde las cuales los y las jóvenes construyen ciudadanías en la ciudad de Medellín", este artículo revisa los ámbitos y los escenarios en los cuales están participando los y las jóvenes de Medellín, desde su adscripción o membrecía a distintos grupos, organizaciones, redes o colectivos juveniles. En este sentido, este artículo delimita las nociones de ámbitos y escenarios, al tiempo que ofrece una visión panorámica de los colectivos juveniles que intervienen desde sus prácticas en cada uno de los seis ámbitos identificados, ellos son: político instituido, político desde la disidencia y la resistencia; reconocimiento a la diversidad; socialcomunitario; lúdico y deportivo; y, estético.
\end{abstract}

Palabras clave: participación política, organizaciones juveniles, colectivos juveniles, resistencia

* Este artículo de investigación científica y tecnológica, presenta resultados de la investigación "Prácticas de Participación Política Juvenil desde las cuales los y las jóvenes construyen ciudadanía en la ciudad de Medellín", financiada por la Universidad de Medellín.

Licenciada en Español y Literatura y magíster en Docencia de la Universidad de Antioquia. Coautora del libro Construcción de identidad y función política en el discurso del director de comunicaciones. Compiladora-editora, junto con Luis Alfonso Ramírez Peña, del libro Estudios del discurso en Colombia. Autora de diversos artículos sobre análisis del discurso. Actualmente es docente-investigadora en la Universidad de Medellín, en la categoría de asociada e integrante del grupo de investigación Discurso, Organización y Política. - Historiadora y magíster en Estética: Culturas urbanas Contemporáneas. Autora de los libros Devenir hombre / mujer. Paso de la Villa de la Candelaria a la ciudad de Medellín; Nos-Otros los jóvenes; y coautora del libro Juventud, investigación y saberes. Estado del arte del conocimiento en juventud en Medellín. 2006-2008. Actualmente, docente de la Facultad de Comunicación, Universidad de Medellín y líder del Grupo de Investigación Discurso, Organización y Política agarces@udem.edu.co / culturasjuveniles@gmail.com

-.. Grupo adscripto a la Facultad de Comunicación de la Universidad de Medellín, desarrolla dos líneas de investigación: Discurso y Comunicación, Comunicación y Culturas juveniles. Actualmente se encuentra en Categoría B, medición COLCIENCIAS 2008. 


\title{
YOUNG POLITICAL PARTICIPATION ENVIRONMENTS AND SCENARIOS IN MEDELLIN
}

\begin{abstract}
In the research "Practices of Juvenile politics from which young people construct citizenships in Medellin city," this article reviews environments and arenas in which Medellin young people are participating, from their subscription to different groups, organizations, networks or juvenile groups. In this sense, this article limits the concepts of environments and arenas and, at the same time, offers a panoramic vision of juvenile groups participating from their practices in each one of the six identified environments: instituted political environment, political environments from the dissidence and resistance; recognition to diversity; socialcommunity; leisure, sporting, and aesthetic environments.
\end{abstract}

Key words: political participation, juvenile organizations, juvenile groups, resistance. 


\section{INTRODUCCIÓN}

Un lugar común en los estudios de juventud es la tendencia a la construcción de una imagen homogénea del sujeto joven que -se suponecorresponde a cada época o momento histórico. En esta perspectiva se termina por asumir que los y las jóvenes comportan idénticas características y modos de ser y de actuar en el mundo por el hecho de compartir similares condiciones históricas. De hecho, cuando se indaga por los modos de participación juvenil, la mayoría de los estudios -con muy pocos repliegues-coinciden en señalar similares argumentos para responder a quienes -frente a los bajos índices de participación de los y las jóvenes en los comicios electoralesterminan por catalogarlos como "apáticos políticos". Así, por ejemplo, se suele argüir que los jóvenes no se alejan de la política sino de las formas tradicionales de ejercerla; que desconfían de la política partidaria; se esgrime, además, que la concepción de poder que interesa a ellos y a ellas es aquella que se construye en colectivo, que supone relaciones de horizontalidad entre sus miembros y que, en definitiva, marca una enorme distancia con respecto a la concepción del poder que ha caracterizado las prácticas políticas tradicionales y hegemónicas, es decir, el poder que se ejerce sobre otros.

Desde otro ángulo se plantea que los y las jóvenes están reinventando la política y lo hacen en prácticas y escenarios de enunciación que son más cercanos a sus modos de sentir, de pensar y de gozar, de soñar, de interactuar con Otros. La política habita entonces los espacios de sociabilidad, las expresiones juveniles que se actualizan en el arte, el baile, la música, el grafito, el esténcil, la lúdica, los escritos en el cuerpo, etc.

En el trasfondo de estos y otros argumentos, que intentan caracterizar al joven de esta época, así como sus modos de participación y acción política, está la imagen unificada, idealizada y cristalizada de un sujeto joven que ha sido construido por los estudiosos de la juventud, pero que puede distar mucho de lo que en efecto ocurre con la constitución misma de el sujeto joven que, al actuar en una pluralidad de ámbitos o esferas sociales y de escenarios, no puede definirse de manera esencialista; de ahí se advierte la imposibilidad de congelar en una imagen unificada la condición juvenil. Los y las jóvenes de esta época, al igual que los y las jóvenes de otras épocas pasadas se mueven, sienten, experimentan, recrean en una diversidad de escenarios y ámbitos que es necesario indagar en su particularidad para evitar caer en la falacia de una imagen generalizada .

Si bien compartimos muchos de los postulados de los estudios de juventud y, particularmente aquellos que abogan por una ampliación del sentido de lo político, también defendemos la hipótesis de que un número importante de jóvenes le está apostando a unos modos más clásicos de participación política. En definitiva, los y las jóvenes participan en una gama muy amplia de ámbitos, no todos ellos de naturaleza política, y por ello hay que afinar la mirada para des-cubrir sus propias lógicas y no aquellas que han sido pensadas y que circulan y transfieren imágenes que distan mucho de lo que ocurre en cada contexto de actuación.

En este orden de ideas, uno de los resultados que arroja la investigación Prácticas de participación política juvenil desde las cuales los y las jóvenes construyen ciudadanías en la ciudad de Medellín es, justamente, la comprensión del carácter disímil y heterogéneo de la participación política juvenil.

Bajo esta comprensión de la participación política juvenil, este artículo propone un recorrido por los ámbitos y los escenarios en los cuales los y las jóvenes de Medellín, desde su adscripción a grupos, organizaciones, redes y colectivos están participando. Para efectos de su desarrollo, y por razones metodológicas, el texto se estructura de la siguiente manera: en primer lugar, se presenta una síntesis de la ruta metodológica que marcó los recorridos de la investigación que nos ocupa. En segundo lugar, se ofrece una delimitación conceptual de los ámbitos y de los escenarios de 
participación juvenil en Medellín, acompañada de una presentación de los grupos, organizaciones, redes o colectivos que fueron identificados para cada ámbito. Por último, se presentan algunas conclusiones en lo que respecta a la participación política juvenil en la ciudad de Medellín.

\section{RUTA METODOLÓGICA}

Una ruta metodológica es un conjunto estructurado de estrategias, procesos, procedimientos, métodos y técnicas que, en su conjunto, constituyen una ruta de trabajo que permita, además de un acercamiento riguroso al objeto de indagación, el logro de los objetivos propuestos. En el marco de esta definición, se señalan a continuación los elementos clave del trayecto metodológico que marcó la ruta en la investigación "Participación política en la construcción de ciudadanías juveniles en Medellín". Esta investigación se realizó en dos fases: la primera de ellas centrada en la revisión de la producción bibliográfica (estudios, investigaciones, análisis y reflexión) en Latinoamérica, Colombia y Medellín. Esta revisión se hizo a la luz de cuatro categorías: participación política; ciudadanías; organizaciones y colectivos; y, prácticas y expresiones juveniles. El resultado obtenido fue la construcción de un estado de la cuestión que sirvió de base para afinar la mirada sobre los modos de acercamiento al objeto, la participación política juvenil, y de esta forma estructurar el trabajo de campo.

La segunda fase enfatizó en el trabajo de campo y, en tal sentido, se orientó a la exploración de las modalidades de participación juvenil en Medellín con miras a su caracterización.

A partir de los resultados obtenidos en la primera fase de investigación y con el fin iniciar la pesquisa sobre la participación política de los y las jóvenes de Medellín, se construyó un directorio de grupos, organizaciones y colectivos juveniles, a la luz de una matriz de observación con dos parámetros de clasificación: el ámbito o esfera de actuación y el escenario (lugar de relación, interacción y enunciación), Es así como, de manera intuitiva, se determinaron seis ámbitos: político instituido, político disidente, social-comunitario, reconocimiento a la diversidad; lúdico-deportivo; estéticoartístico. La consideración de cada ámbito fue abriendo un abanico de escenarios en los que los y las jóvenes participan.

No obstante contar con una matriz de observación, el proceso sufrió múltiples inconvenientes; en primer lugar, porque -si bien se han realizado en Medellín diagnósticos rápidos participativos por comunas- no se cuenta con un mapa de ciudad que ofrezca un panorama de la existencia y trayectoria de los grupos u organizaciones juveniles en la ciudad; en segundo lugar, a la hora de pensar las formas de participación juvenil se abordan desde las organizaciones tradicionales e institucionalizadas, dejando al margen las características mismas de la población juvenil y sus modos de configuración grupal que algunos teóricos (Valenzuela, 2007; Reguillo, 2000; Delgado,2007; Zarzuri, 2005) han denominando colectivos juveniles; en tercer lugar, como es habitual que los investigadores conversen con pares que han vivido o están viviendo procesos de búsqueda similares, las bases de datos y los contactos con los colectivos juveniles son bastante restringidos, al punto de terminar investigando siempre los mismos colectivos (Red Juvenil, CMJ, entre otros); en cuarto lugar, en la medida en que no hay un consenso en términos de lo que significa lo político y, por ende, de los criterios para determinar el carácter político de una acción, persisten dos riesgos con los que hay que lidiar cuando se intenta abordar el tema de la participación política: bien un cierre del sentido de lo político que confina la participación política a los comicios electorales, bien una ampliación exacerbada del término que termina en una generalización a partir de la cual toda acción y toda práctica son políticas.

A fin de ir subsanando algunas de estas dificultades, se tuvo en cuenta, en primer lugar, el acudir a la experiencia acumulada de 
investigadores en el tema de participación política juvenil con el fin de evitar atajos innecesarios; en segundo lugar, la identificación de fuentes de primera mano que trabajan con los y las jóvenes de la ciudad; en tercer lugar, las bases de datos de instituciones que trabajan con juventud; finalmente, la experiencia y los conocimientos de los investigadores del grupo. Si bien, el proceso de identificación no fue exhaustivo, en razón de que no se ocupa de la totalidad de las organizaciones y colectivos juveniles de la Ciudad, sí se logra una profundidad en tres de los ámbitos que se seleccionaron para esta investigación, ellos son: político instituido; político desde la disidencia; y, reconocimiento a la diversidad en perspectiva de mujer.

Una vez se tuvo un panorama de los grupos, organizaciones o colectivos existentes en la ciudad, se procedió a la aplicación de una guía de entrevista con los colectivos. Este instrumento se estructuró desde las siguientes categorías: datos de contextualización; origen y trayectoria; conformación y funcionamiento; identidad y acción; y, modos de relación y comunicación. De manera simultánea, se organizó una serie de conversatorios por ámbito de participación, de tal manera que la información obtenida por medio de la guía pudiese ser contrastada en otros escenarios de enunciación. Sin embargo, de los conversatorios previstos solo se realizaron dos, situación que obligó a la programación de entrevistas a profundidad con actores clave para cada uno de los ámbitos.

El análisis de la información obtenida, mediante la aplicación de las técnicas y de los instrumentos señalados, permite la construcción de una matriz de análisis que rectifica y supera las limitaciones de la matriz de observación, entre ellas la dispersión de ámbitos, y el carácter lineal en la ubicación de los colectivos en uno u otro escenario; y, finalmente, el reconocimiento de categorías de análisis que, en su conjunto, aproximan a una caracterización de las modalidades de participación política en perspectiva juvenil, en los ámbitos seleccionados.

\section{ÁMBITOS Y ESCENARIOS DE PARTICIPACIÓN POLÍTICA JUVENIL}

Entendemos la participación juvenil como el tipo de prácticas o el conjunto de acciones a partir de las cuales los y las jóvenes, en calidad de actores sociales con sus necesidades, experiencias y potencialidades, ejercen, no solo el derecho a ocuparse de los asuntos de su interés, sino también su aspiración y su lucha porque Otros actores sociales reconozcan, respeten y legitimen sus modos particulares de ser, de sentir, de expresar, de actuar, de organizarse y de intervenir en pro del logro de sus proyectos, deseos, sueños, aspiraciones, intereses, y en la realización de sus proyectos; todo ello en el marco de la Constitución, la ley y el respeto del Otro que ofician como el límite externo de su constitución subjetiva.

Por ello, en la presente investigación de "Ciudadanías juveniles" nos inclinamos a decir que la participación juvenil, al igual que la participación de cualquier actor social, suele adscribirse en unos ámbitos o esferas de actuación en la vida social; ejercerse en una pluralidad de escenarios (lugares de relación e interacción); orientarse desde una gama de finalidades(visiones y orientaciones de la acción e interacción); responder a unos determinados propósitos (macrotemas o asuntos que los convocan); y, actualizarse en una pluralidad de modalidades (maneras o modos que caracterizan una intervención, en atención tanto a las características y a las opciones de los grupos o colectivos juveniles, como a las condiciones de los escenarios, las finalidades y los propósitos que los convocan).

Es necesario precisar que la ubicación de ámbitos y escenarios de participación obedece a razones metodológicas, pues, en la práctica la participación política juvenil puede adscribirse a más de un escenario; así por ejemplo: un joven puede hacer parte de una organización partidista, al tiempo que puede estar adscrito a escena- 
rios de disidencia o de resistencia al pertenecer a un colectivo que abrogue por los derechos a la diversidad sexual o étnica.

Para el caso de la investigación en ciudadanías juveniles, se han determinado siete ámbitos en las que los y las jóvenes de Medellín están participando o manifiestan una inclinación por la participación, ellos son: político instituido-político desde la disidencia o la resistencia; reconocimiento de la diversidad; social-comunitario; deportivo (lúdico-recreativo); estético-artístico.

\section{1. Ámbito político instituido}

En términos generales, la participación política ha estado restringida, por un lado a los mecanismos de participación dispuestos por los sistemas de representación política, de los cuales el voto y el referendo ocupan un lugar protagónico; por otro lado, a la contienda por el poder o su opuesto la resistencia. En el primer caso y en el marco de apuestas políticas que se muestran proclives, por convicción o por estrategia política, a la implementación de mecanismos de participación más cercanos a la democracia directa, los mecanismos de participación política se amplían a escenarios de veeduría ciudadana, y seguimiento y control de las actuaciones de los gobernantes. En el segundo caso, lo político se amarra a la lucha por el poder en el que los grupos implicados intentarán hacer prevalecer sus intereses y su visión del mundo.

El ámbito político instituido en perspectiva juvenil comprende un cuerpo de escenarios en los que los y las jóvenes deciden estar, bien sea porque aceptan participar en los mecanismos de participación que contemplan la Constitución y la Ley y que actualizan los entes gubernamentales, o bien porque deciden vincularse a organizaciones o movimientos sociales que abanderan sus propias causas y que gozan del reconocimiento, la aceptación e incluso el apoyo de los entes estatales.
En este ámbito se identificaron los siguientes escenarios de participación juvenil: CMJ, red de personeros, personeras y representantes estudiantiles de la ciudad de Medellín y los cinco corregimientos; las organizaciones de jóvenes en la política partidista; la adscripción de jóvenes en movimientos $u$ organizaciones sociales que abanderan causas y proyectos sociales.

\section{- Consejo Municipal de Juventud. CMJ}

En agosto de 1994, mediante el acuerdo 007 del Concejo de Medellín, se crea el CMJ como "Organismo asesor-consultivo de la Administración municipal para la formulación y ejecución de todos los planes y programas que tengan relación con la población juvenil del municipio", y en 1995, con la expedición de la Ley de Juventud, empezó a funcionar y lo ha hecho sin interrupciones por períodos de tres años.

Actualmente el CMJ lo conforman 9 jóvenes independientes (cada uno debió recoger mil firmas para presentarse a las elecciones), 6 representantes de organizaciones juveniles (Juventudes Liberales, Nuevas generaciones partido conservador, MIRA, entre otros) y 4 personas pertenecientes a las minorías étnicas que se eligen por votación entre sus mismas etnias (raizales, afro colombianos, comunidades indígenas, jóvenes rurales). Se debe resaltar que el ingreso al CMJ está condicionado por el número de votos que obtenga el candidato. La mayoría de sus integrantes están en el rango de edad de los 18 a los 26 y todos los integrantes cumplen las mismas funciones dentro del CMJ exceptuando la presidencia colegial (terna elegida por votación y que ocupan los consejeros por un período de 6 meses).

\section{- Gobierno escolar. Red de personeros, personeras y representantes estudiantiles}

La Red surge de la necesidad de fortalecer y posicionar las figuras de personero/a y representante estudiantil en la ciudad de Medellín y sus corregimientos. En tal sentido, busca agrupar ideas y aunar esfuerzos para luchar por el respeto de los derechos de los (as) niños 
(as) en las instituciones educativas. Asimismo, es propósito de la Red mantener un diálogo permanente y el intercambio de experiencias que ayuden a consolidar los procesos de liderazgo y participación de los jóvenes y que, a la vez, las iniciativas que surjan de manera conjunta sean tramitadas a través de diferentes instancias públicas. Esto permitirá ganar en organización, reconocimiento de las propuestas de los jóvenes y adolescentes, y establecer canales de comunicación e intercambio con la Administración municipal para atender, de manera efectiva, la problemática de los jóvenes partiendo de las soluciones que ellos mismos aporten.

Según información suministrada por uno de sus miembros, la Red cuenta con 60 integrantes; sin embargo, la Red contempla distintas figuras de participación: miembros dinámicos, integrante virtual, integrante activo, capacitador y participante. Los temas o asuntos que los congregan son: derechos humanos, libre desarrollo de la personalidad, objeción por conciencia; debido proceso; participación y violencia juvenil. La Red mantiene relación y recibe el apoyo de la Personería, ente que actualmente lidera el programa "Democracia Escolar", y la Administración municipal a través de Metrojuventud.

\section{- Organizaciones de jóvenes en los partidos políticos}

La mayoría de los partidos políticos tienen entre sus estrategias de consolidación aquella que apunta al relevo generacional y, en tal sentido orientan acciones tendentes a cooptar a los y las jóvenes. En este contexto, la investigación logró identificar las siguientes organizaciones juveniles, adscritas a los movimientos o partidos políticos colombianos que tienen fuerza y asiento en Medellín.

\section{Juventudes Liberales}

En la página $W^{1}{ }^{1}$ se declara que la Organización Nacional de Juventudes Liberales

1 http://www.juventudesplc.com/comoParticipamos.php
(ONJL) de Colombia es el espacio de participación de los jóvenes asambleístas liberales. Tiene relativa autonomía en la toma de decisiones frente a las directivas del partido y fue creada tras la reforma estatutaria de 2002. Pueden ser miembros de la ONJL colombianos entre los 14 y 26 años, pero solo los mayores de 18 años son elegibles a cargos.

Actualmente la ONJL tiene presencia en más del 90\% de los municipios de Colombia.

Según las declaraciones de los miembros de Juventudes Liberales de Antioquia, posterior a la consulta abierta del Partido Liberal (realizada el 27 de septiembre de 2009), la organización está compuesta por 26 jóvenes que forman la base del equipo. Tal y como se expone en los estatutos de la Organización Nacional de Juventudes Liberales, esta es la unión de jóvenes y organizaciones juveniles políticas colombianas que, en atención a lo contemplado en el artículo 51 de los estatutos del Partido Liberal, lucha por la democracia y la igualdad de oportunidades sociales, educativas y laborales de los y las jóvenes colombianas.

\section{- Nuevas Generaciones Partido Conservador Colombiano}

Según se declara en la página Web, Nuevas Generaciones es la organización del Partido Conservador Colombiano que se encarga de fomentar y garantizar la participación política de los jóvenes en los diferentes espacios que con este objeto se crean. De igual modo, propende por capacitar a todos los jóvenes en la historia, doctrina y pensamiento del conservatismo colombiano, así como proporcionarles las herramientas necesarias para ejercer un liderazgo propositivo, que entienda la política como la búsqueda del bien común y el servicio a la comunidad.

En conversaciones sostenidas con algunos de sus miembros, estos afirman que a pesar de que "Nuevas Generaciones" surgió en el 2001, su actividad real comienza en el 2005, pues en los cuatro años que comprendió este período 
los jóvenes que participaron eran en su mayoría hijos de "caciques" políticos que los nombraban a dedo y los hacían participar de las actividades del partido sin que ellos tuviesen interés alguno en hacer parte de él. Sólo hasta el 2005 se logró comenzar un proceso de fortalecimiento de Nuevas Generaciones con jóvenes que ingresaban al partido y al grupo por voluntad propia y con la convicción de trabajar por él. Desde las elecciones de representantes departamentales en el año 2008, Nuevas Generaciones Antioquia viene desarrollando actividades sin ninguna interrupción.

En el directorio departamental del partido debe haber mínimo 3 jóvenes elegidos por votación popular en la consulta conservadora abierta que se llevó a cabo en el 2008. De estas consultas salieron elegidos para el directorio departamental 5 jóvenes, 3 mujeres y 2 hombres. Estos 5 jóvenes se encargan de convocar a una asamblea de nuevas generaciones en la cual los jóvenes asistentes (en el 2008 asistieron aproximadamente 200 jóvenes representantes de todo el departamento) escogen quién de estos 5 debe ser el coordinador departamental.

\section{- Polo Joven}

Según las declaratorias de algunos miembros de este colectivo, su constitución se da formalmente en el primer congreso nacional del Polo Democrático Independiente en 1999 en donde se plantea la división del partido por grupos poblacionales, entre ellos los jóvenes, atendiendo también a la necesidad de crear cultura y participación política en la población juvenil en Colombia. En este mismo congreso se determinó que de cada uno de estos comités regionales juveniles saldría un representante elegido democráticamente en el interior del grupo para participar como delegado ante el comité regional.

Desde su creación, el trabajo de Polo Joven ha sido constante y sin interrupciones, con reuniones quincenales o mensuales según las ne- cesidades; actualmente cumple 10 años de creación que se celebraron con el Primer Congreso Nacional de Polo Joven que se realizó en Ibagué en el mes de febrero de 2009.

Polo Joven está integrado por jóvenes que provienen de todas las comunas de la ciudad, pero la mayoría de los miembros pertenecen a las universidades públicas de Medellín (Universidad de Antioquia - Universidad Nacional Sede Medellín). También hacen parte de Polo Joven algunos jóvenes de otros municipios del Área Metropolitana como Bello, Itagüí, La Estrella, Envigado y Sabaneta.

\section{- Jóvenes Fajardistas}

Este colectivo surge en la Administración municipal de Sergio Fajardo en Medellín. En los comicios electorales para la elección de alcalde en Medellín en el período 2008-2011, apoyó la elección del alcalde Alonso Salazar. Actualmente, el movimiento de Jóvenes Fajardistas se revitalizó con el acompañamiento a la campaña para la presidencia del candidato Sergio Fajardo.

\section{- Movimientos étnicos: Cabildo Chibcariwak}

En la categoría de Etnia, según información suministrada por el Cabildo Indígena en la ciudad, están asentados grupos indígenas pertenecientes a 21 comunidades, que vienen de otros departamentos y municipios de Antioquia. Algunas de estas comunidades son: Tules, Ningas, Embera Chamí, Embera Katíos, Zenúes, Taironas, Wuayúu, Arahuacos, entre otros. En la ciudad de Medellín se conformó el Cabildo Chibcariwak que reúne un amplio grupo de hombres y mujeres indígenas jóvenes, que tienen en común su condición de población desplazada de forma forzada, y en la ciudad de Medellín empiezan la dura labor de agruparse en pro de la defensa de los derechos humanos básicos en zonas urbanas marginales (Ver: diagnóstico de Población Indígena en Medellín. Alcaldía de Medellín. 2008). 
Con 30 años de actividad, Chibcariwak cuenta con 3.800 integrantes, cuya mayoría se ubica en los siguientes barrios de Medellín: Andalucía la Francia, cerca de la estación del metro Acevedo, Medellín; Llanaditas, llegando a la Sierra; 12 de Octubre; Belén; Prado; y, San Diego. De este número de integrantes, aproximadamente 200 se consideran miembros activos.

\section{2. Ámbito políticodesde la disidencia y la resistencia}

Aunque este ámbito no es exclusivo del sujeto joven, sí es éste el que resulta más proclive a la lucha contra el poder hegemónico y sus formas de representación y control. En este contexto, disidencia y resistencia son dos modos de asumir posición con respecto a las prácticas hegemónicas; la primera de ellas, es decir, la disidencia puede expresarse, bien en un distanciamiento frente al universo cognitivo dominante (sistemas de ideas o creencias; elaboración de relatos que construyen sentidos colectivos ); en este caso se trata de un "disidir" o, bien, en un distanciamiento frente al universo emocional o los modos del sentir (las estéticas; los estilos de vida y las expresiones artísticas), en cuyo caso se trata del "disentir" o del sentir diferente.

De otro lado, tal y como lo afirma José Reinel Sánchez ${ }^{2}$ (S. F.), la disidencia, en su sentido clásico, presenta diversas formas así: inconformismo silencioso: actitud que no manifiesta su rechazo a las disposiciones pero que crea malestar y aflora como resentimiento; inconformidad manifiesta es al acto clásico de disidencia en la que el agente dice que no está de acuerdo con la disposición política y da razones públicas de su inconformidad; objeción de conciencia, cuando el agente, amparado por razones de conciencia, objeta rotundamente el cumplimiento de una disposición y no la cumple; su campo de acción se reduce a lo privado aunque esto sólo es

2 Artículo publicado inicialmente en la REVISTA Universidad del Quindío. Armenia, Quindío. Colombia-Suramérica. Vol. 1, № 6 . 2008. pp. 5-17. inicialmente; desobediencia civil, desobediencia manifiesta a una disposición, emplea métodos públicos y pacíficos; resistencia, enfrentamiento directo en contra de un régimen; se caracteriza por el uso de la fuerza física.

En el contexto de la participación juvenil, existe la intuición de que las modalidades de disidencia y de resistencia se materializan fundamentalmente a partir de las expresiones estéticas y artísticas; por supuesto, no se descarta su actualización en otras esferas o escenarios de acción como por ejemplo: grupos de jóvenes que, explícita y abiertamente, critican los modos y las prácticas de los partidos políticos y aquellos que abanderan pequeñas causas, generalmente de los grupos excluidos; ejemplo concreto: "los desconectados", objeción por conciencia, entre otros. En todos estos casos lo que al parecer se pone en cuestión son las construcciones de sentido que apuntan a la configuración de una realidad y a la definición de unos modos de actuar frente a los cuales los jóvenes, bien toman distancia con respecto a esas realidades construidas y se repliegan en sus propias realidades, o bien construyen sus propios horizontes de sentido, en los cuales despliegan su sensibilidad y su energía vital. Es este último caso donde la música y, en general, el arte se configuran como referentes políticos, puesto que, además de congregar voluntades se configuran como puntos nodales en la construcción de las identidades juveniles. Las expresiones estéticas en su conjunto ofrecen a los jóvenes la posibilidad de disidir o de resistir por la capacidad misma que tiene el componente estético para transgredir los órdenes establecidos. De tal manera que, en la música, el baile, el arte gráfico (el esténcil, el grafito, entre otros) los y las jóvenes encuentran una posibilidad para constituirse como sujetos políticos.

Los escenarios que configuran el ámbito de disidencia y resistencia son: grupos de estudio y colectivos juveniles que se con-forman en torno al arte, la música y las expresiones de contracultura y contrapoder. 


\section{- Grupo de Estudio OtraEzcuela}

Con su lema "Solo para Inconformes", Otraezcuela ${ }^{3}$ se crea en el 2004 en un paro de la Universidad de Antioquia de más o menos 4 meses, por un decreto que iba a hacer un recorte en el plan de estudios. Nació como Escuela Estanislao Zuleta de la Universidad de Antioquia. Luego nace la Escuela de Itagüí. La propuesta se va multiplicando y se crean otras sedes en Marinilla, San Antonio de Prado, en Bello. Diferentes personas se unen en torno a la reivindicación de Estanislao con influencia del Polo Democrático. Se desconocen qué actividad tengan hoy esas organizaciones. Hace dos años, por divisiones en el interior del grupo, se transforma el proyecto inicial y seis de sus integrantes se separan y abren OtraEZcuela. El motivo de la creación del grupo, que aún guarda el mismo sentido para sus seis integrantes, fue el deseo de juntarse par a formarse políticamente y reflexionar sobre las coyunturas y las realidades del país, con el ánimo de estudiar la política, orientados en un pensador tan brillante como Estanislao Zuleta.

\section{- Red Juvenil: Grupo Objeción por conciencia (ART) ${ }^{4}$}

Según se declara en la Pág. Web La Red Juvenil nace en Medellín en 1990, en un contexto que, marcado por la violencia, implicó abiertamente a los y las jóvenes de Medellín, bien en calidad de víctimas, o bien en su vinculación a cualquiera de los bandos enfrentados en el conflicto. En este contexto, la propuesta de la Red Juvenil fue articular propuestas de diversas organizaciones juveniles a fin de fortalecer el trabajo en red y la formación de jóvenes como sujetos sociales que pudiesen incidir en el desarrollo de la Ciudad. Lo anterior, a fin de debilitar la imagen de amenaza o vulneración que la ciudad fue construyendo de los y las jóvenes de Medellín.

3 http://otraezcuela.blogspot.com/2008/05/otraezcuela-en-laresistencia-creativa.html

4 http://www2.redjuvenil.org/content/category/2/59/31/
A finales de la década del 90 y la primera del siglo XXI, la participación de la Red en los Planes Trienales Juveniles evidenció las fortalezas organizativas y políticas de La Red que asume como referentes de trabajo y acción la Objeción por Conciencia, la No Violencia Activa, la Resistencia Civil, el Empoderamiento Juvenil y los Derechos Juveniles. El grupo Objeción de Conciencia es un colectivo constituido por hombres y mujeres que han tomado la decisión de declararse objetores y objetoras a la guerra y cualquier forma de injusticia y de sistemas de control. Bajo esta convicción, Objetores por Conciencia asumen una posición antimili y en ella la negación a participar de cualquier ejército (militar, paramilitar o guerrilla). En el Antimilitarismo Sonoro, se reúnen múltiples músicas y bandas que abarcan punk, metal, reggae, hip hop, ska, electrónica.

La experiencia y el trabajo que ha abanderado el grupo Objeción por Conciencia, ART, ha sido reconocido por el Banco de Buenas Prácticas para Superar el Conflicto -Programa de Naciones Unidas para el Desarrollo- Colombia ${ }^{5}$.

\section{- Corporación Artística Popular "Cultura y Libertad"}

Es un colectivo con 3 años de existencia que congrega, desde el referente del Hip Hop a los y las jóvenes de 6 comunas de Medellín y del municipio de Sabaneta. Aunque no es un dato exacto porque permanentemente están incursionando jóvenes, en la actualidad el colectivo reúne poco alrededor de 200 jóvenes que creen en el Hip Hop como herramienta de transformación. El principal motivo para la creación del colectivo fue la necesidad de articular y fortalecer propuestas que, desde los barrios, estaban y están surgiendo en torno a la creación de grupos y de escuelas de Hip Hop con la idea de restarles jóvenes al conflicto.

\footnotetext{
5 http://www.saliendodelcallejon.pnud.org.co/buenas_practicas. shtml?x=7065

6 http://www.myspace.com/culturaylibertadudea
} 
Como lo expresa "el Mocho", Cultura y Libertad nació con 20 niños y hoy cuenta con 40 bailarines, según él, cada vez luchando por robarle jóvenes al conflicto. Leandro, otro de sus integrantes, afirma que los tres vectores de este colectivo son: crear escuelas artísticas populares en las comunas; formar a los jóvenes de Medellín en la gestión y el desarrollo de proyectos sociales y culturales; y, fortalecer las redes artísticas.

\section{3. Ámbito Reconocimiento a la Diversidad}

Este ámbito es un emergente que encuentra asidero y respaldo en el discurso que aboga por los derechos y el desarrollo humano; discurso que intenta, por un lado, moderar el impacto negativo de la implementación del modelo neoliberal, que abrió la brecha de la desigualdad y el desequilibrio social, y por otro lado, responder al incremento de las demandas de grupos sociales excluidos, entre ellos: afrodescendientes, mujeres, comunidad LGTB e indígenas.

La población juvenil ha sido proclive a las reclamaciones de los derechos de las minorías y en tal sentido se han movilizado, bien en el marco de brindar apoyo a los movimientos sociales que abanderan estas luchas por la visibilidad y el reconocimiento de sus derechos; bien en el marco de organizarse o de constituir sus propios espacios o colectivos juveniles para hacer valer sus derechos o defender causas que consideran justas. En este contexto es propio intuir que la inclusión se constituye, no solo en un referente que congrega a los jóvenes, sino también, en un potente detonador en la construcción de las identidades juveniles. Consideramos a continuación dos categorías de la diversidad, género y opción sexual diversa, para reconocer los escenarios donde los y las jóvenes logran redimensionar la participación política.

\section{Categoría género}

En la labor preliminar de identificación de formas de participación política juvenil en la categoría de género en Medellín, sobresalen varias experiencias y proyectos desarrollados por organizaciones no gubernamentales. Se trata de corporaciones con una trayectoria de más de 20 años de existencia, preocupadas por el diálogo generacional; se destacan: Corporación Vamos Mujer, Mujeres Que Crean y Red Juvenil; se resaltan las siguientes propuestas articuladas a dichas organizaciones:

\section{- Agenda Mujer}

Nace en la Corporación Mujeres Que Crean ${ }^{7}$, se orienta a mujeres jóvenes y adultas, para la construcción y concertación de sus propias agendas como herramientas de acción y movilización socio-política. La Agenda Mujer se plantea en dos ejes temáticos importantes: el desarrollo local y la gestión del desarrollo, y la vivencia de la democracia a través de los derechos como ejercicio pleno de ciudadanía. Desde esta perspectiva los temas que desarrolla este programa son: planeación del desarrollo con perspectiva de género y generacional; democracia y ciudadanía de las mujeres; agendas ciudadanas de las mujeres; mujeres jóvenes en ejercicio de su ciudadanía; y, fortalecimiento y consolidación de las organizaciones de mujeres.

\section{- Colectivo de Mujeres Jóvenes}

Mujeres Jóvenes en Medellín, después de transitar por varios procesos organizativos, se reúnen, desde diversas procedencias (artísticas, estéticas, comunitarias) a manifestarse como Colectivo de mujeres jóvenes, en momentos clave de "conmemoración de la mujer", para manifestar su disidencia y voz propia. También se reúnen y movilizar alrededor de los derechos humanos de la mujer y de causas como el respeto de los derechos sexuales y reproductivos, por una sociedad justa que reconozca la diversidad.

\section{- Red de Mujeres Jóvenes Talento:}

En el ámbito de participación política instituida es necesario relacionar el proyecto

7 http://www.mujeresquecrean.org/pgmadllo.htm 
de "Mujeres Talento". Se origina en el año 2004, promovido por la Secretaría de la Mujer de la Alcaldía de Medellín, para reconocer y resaltar la labor de las mujeres jóvenes en sus diversas acciones sociales, comunitarias y académicas. El proyecto de Mujeres Talento busca promover el posicionamiento, valoración y reconocimiento social de las mujeres jóvenes de Medellín, por lo que son capaces de hacer, pensar y sentir", afirma Rocío Pineda, Secretaria de las Mujeres . Por decreto, se determina la realización de una versión anual del concurso Mujeres Talento, en el marco de la Feria de las Flores con el propósito de incidir en el cambio de esquema tradicional de participación de las mujeres en los concursos y reinados.

Actualmente las "Mujeres Talento" se reúnen como grupo dinamizador de propuestas propias, donde le dan continuidad a su origen de "romper el paradigma de la mujer modelo y reina a través del acciones directas, donde se busca revisar el patriarcado, promover la equidad de género y pensar el nuevo feminismo". En principio, las "Mujeres Talento" han tratado de conformar una Red Mujeres, donde reciben formación en participación política, acción ciudadana y formas de organización de mujeres en la ciudad de Medellín. Las Mujeres Talento se debaten entre la política instituida y disidente, pues no pueden dejar atrás su origen, nacen de un concurso alternativo a los reinados de belleza, y están adscritas al presupuesto de inversión anual de la Alcaldía de Medellín; pero a su vez, quieren realizar acciones propias sin vincularse a proyectos de Estado.

\section{Categoría Opción sexual diversa}

En la categoría de opción sexual diversa, se logra identificar jóvenes que vienen haciendo parte de los escenarios de reivindicación de los derechos humanos de la población LGTB; es por esto, que en sus narraciones se encuentran vivencias que

8 www.culturaemedellin.gov.co/sites/CulturaE/CulturaE/Noticias/ Paginas/mujerestalento2009 09

9 Entrevista a Laura Vallejo Velásquez. Octubre 17 de 2009. muestran un mayor acercamiento entre ellos(as), con la familia y con la mirada social frente a su condición sexual. En la ciudad de Medellín existen corporaciones y movimientos con amplia trayectoria en el reconocimiento de la diversidad LGTB, considerado un movimiento que reúne a lesbianas, gais, transexuales y bisexuales; sobresalen los siguientes agrupaciones:

\section{- Corporación El Xolar}

En la búsqueda de una mayor proyección política LGBT, El Xolar opta por la reconstrucción de la memoria colectiva -incluyendo la obra de León Zuleta-, renuncia a la bandera estigmatizante del VIH/SIDA -que, entre otras cosas, copa los escasos recursos del sector y suple al Estado en la obligación de velar por la salud pública- y prioriza las alianzas en el ámbito nacional con otros grupos sociales tradicionalmente excluidos en defensa de los derechos humanos. En desarrollo de la estrategia cultural que pueda hacer frente a la homofobia, El Xolar ha movilizado el "Día del No a la Homofobia", "El ciudadano gay", "Orgullo Gay".

\section{- Corporación El Otro}

Es una organización que promueve los derechos humanos de las personas con identidades LGTB. Entidad no gubernamental conformada por profesionales en diferentes áreas legales y humanas, que trabajan por la defensa y promoción de los derechos humanos, sociales, culturales, civiles y políticos del sector LGTB de la ciudad de Medellín. Sus objetivos buscan contribuir a los cambios sociales, políticos y culturales en nuestro país, mediante movilizaciones públicas y políticas como Marcha del Orgullo Gay y campañas contra los crímenes de odio en Medellín Colombia / SUR América; sus ejes de trabajo y acción se condensan en derechos humanos diversos, procesos educativos en ética y sexualidad en la diversidad en espacios educativos, sociales, institucionales y familiares. 


\section{- Asociación de Mujeres que Aman Mujeres - AMAN}

Se organiza en Medellín con la firme intención de generar desde su labor social y cultural, proyectos significativos para las mujeres lesbianas, trans, bisexuales e intersexuales, promoviendo espacios de reflexión y acción que enriquezcan el reconocimiento de su identidad y favorezcan el respeto por la diferencia ${ }^{10}$.

\section{4. Ámbito social-comunitario}

El desarrollo de la democracia requiere de ciudadanos organizados y comprometidos con los asuntos públicos, bien en el marco de la intervención en la toma de decisiones que afectan a los colectivos humanos, bien en el marco de la participación en proyectos de desarrollo social y comunitario. En este contexto, intuimos que los y las jóvenes participan, por un lado, desde su vinculación a organizaciones más o menos institucionalizadas (religiosas, culturales, educativas, barriales), lideradas por adultos y que abogan por intereses específicos, según su naturaleza y sus finalidades; por otro lado, en organizaciones propiamente juveniles o colectivos que exhiben, entre sus características, la informalidad, la heterogeneidad de intereses, la horizontalidad entre sus miembros, la precariedad de sus estructuras organizativas.

En este ámbito nos proponemos indagar por las siguientes modalidades de construcción de ciudadanías en relación con voluntariado, procesos de autogestión, pequeñas causas, juntas de acción comunal.

Sobresalen en Medellín varias corporaciones con amplia trayectoria en los procesos de organización comunitaria y desarrollo local zonal, ubicadas particularmente en zonas de amplio conflicto social por conflicto armado diverso, como narcotráfico, sicariato, ubicación de población desplazada, entre otros. Resaltamos en especial:

10 http://medellinamam.blogspot.com/

\section{- Corporación Picacho con Futuro}

Se trata de una organización comunitaria, de segundo grado sin ánimo de lucro que fortalece organizaciones comunitarias, mediante la formación, la capacitación, el acompañamiento, la asesoría y la promoción de estas; posibilitando la gestión participativa del desarrollo local y el empoderamiento social, para contribuir al mejoramiento dela calidad devida, principalmente de los habitantes de la comuna seis, parte alta de la ciudad de Medellín. Está conformada por ocho organizaciones comunitarias de la comuna seis de Medellín, ellas son: Las Asociaciones de Madres Comunitarias Amor y Esperanza y El Triunfo, Juntas de Acción Comunal Santa Teresa y La Pradera, Organización juvenil Juventud Unida Comunicaciones, los grupos de Afectividad y Vida en Familia París y Santa Mariana, el Comité de Deportes Barrios Unidos, la Corporación Comunitaria Antena Parabólica Doce de Octubre y seis organizaciones juveniles que hacen parte de la red de organizaciones juveniles de la comuna seis, parte alta. A su vez, estas organizaciones conforman el Consejo Directivo de la Corporación Picacho con Futuro ${ }^{11}$.

\section{- Corporación Convivamos}

La Corporación Con-Vivamos es una organización comunitaria de carácter popular. Se constituyó el 15 de julio de 1990. Es una organización que promueve el desarrollo local, a partir de la educación popular, la investigación acción participativa, la promoción comunitaria, la comunicación popular y el acompañamiento psicosocial. El modelo de intervención se expresa en lo territorial, lo sectorial y lo poblacional.

La Corporación está compuesta por una Asamblea de socios. Ésta nombra una Junta Directiva y la Dirección General. Además, hay un equipo de trabajo interdisciplinar que desarrolla las acciones de la institución. CONVIVAMOS orienta su intervención con base en planes trie-

11 http://corpicacho.netfirms.com/ 
nales de desarrollo, los cuales son el horizonte estratégico de la corporación ${ }^{12}$. Los jóvenes se encuentran articulados a la Corporación a través de la Red de Organizaciones de la Comuna NorOriental. Desarrollan actividades propias, con miras a la educación popular, la participación política y el desarrollo social y cultural. Entre sus programaciones culturales se destaca Lunadas Juveniles de Resistencia.

\section{5. Ámbito Deportivo (lúdico-recreativo)}

Los discursos sobre el cuidado del cuerpo y el atributo a la belleza han generado una explosión de la práctica deportiva, especialmente en la población juvenil. Si a esto se agrega que este grupo etario -por razones físicas, mentales y culturales (tienen la vitalidad, la capacidad y el interés)-es más proclive a las prácticas deportivas que cualquier otro grupo poblacional, se entiende, entonces, que hay una disposición para que el deporte se convierta en un referente potente, no solo por su capacidad de congregar a los jóvenes, sino también por constituirse en un escenario de encuentros y, por ende, de sociabilidad. Estas condiciones han sido interpretadas por la clase política y tal vez esta sea, cuando menos, una de las razones que explican que, en los programas de los candidatos a las distintas corporaciones se considere la construcción de placas, unidades o diversos escenarios deportivos.

Otra de las razón podría ser la imagen del joven como sujeto problema y vulnerable que se edificó en la década de los 90 y que, si bien se ha menguado, no ha podido superarse. Esta imagen, si bien ha sido nefasta en lo que respecta a procesos de discriminación, segregación y exclusión, también ha servido para que gobernantes y otros actores sociales reconozcan al deporte como una opción para alejar a los jóvenes del vicio y para utilizar, de manera saludable, el tiempo libre.

12 http://www.convivamos.org
Otras consideraciones que caben, en el ámbito del deporte, tienen que ver con las visiones del gobierno (municipal, departamental y nacional), frente a otros escenarios que propician la emergencia de sujetos políticos, al lograr una visibilidad, y a su vez, confrontar el orden social, al configurar formas de organización insólitas y quizá fuera del control policial. El deporte ha sido entonces desde la institucionalidad una estrategia de control del tiempo libre del joven, pero desde la perspectiva juvenil se presentan confrontaciones a la oficialidad. Entre estas manifestaciones podemos mencionar:

\section{- Barristas}

Las barras tienen sus orígenes en los años 60, han crecido vertiginosamente en Colombia, en especial en Bogotá, Medellín y Cali. Su aparición y desarrollo tomó mal preparadas a las autoridades, a los equipos, a los jugadores, a los periodistas. Y también a los espectadores. Sus creadores y líderes reconocen que sus objetivos, de efervescente acompañamiento a sus equipos preferidos, se desviaron, pero dicen estar dispuestos a recuperarlos. Se plantean pactos de no agresión entre las barras. Sus estructuras organizativas son fuertes en relación con la promoción de los hinchas y la visibilidad en el espacio público, que marca las diferencias; también representan intereses grupales de oposición entre las barras, Rexixtenxia Norte, del DIM, Los del Sur, Los de Nacional, los rechazan.

\section{6. Ámbito estético}

En este ámbito los encuentros y agregaciones juveniles cobran sentido de forma diferenciada acorde con la aceptación y promoción del poder establecido o su lucha por el reconocimiento a la diversidad de expresiones y prácticas de juventud. Asimismo, las expresiones juveniles vinculadas con el arte y la cultura pueden adquirir una dimensión política por dos razones fundamentales: en primer lugar, porque son puntos nodales para la construcción de las 
identidades y dicha construcción tiene lugar en un escenario de tensiones en las que el sujeto se ve obligado o tentado a decidir la posición desde la cual aspira a ser reconocido; en segundo, lugar porque las expresiones y las culturas juveniles tienen el poder de congregar voluntades, bien sea por la fuerza y el dinamismo de los formatos, o bien por la fuerza y el sentido de sus contenidos. Es el caso de la música, el baile, el arte gráfico (esténcil, graffiti) y el videográfico (clips); que se convierten en los medios alternativos de comunicación.

Estas consideraciones nos acercan a los planteamientos de José Manuel Valenzuela (2008) cuando alude al concepto de Red simbólica. Se trata de formas de identificación en las cuales los jóvenes participan en la conformación del sentido de la red. Es una suerte de comunidad hermenéutica, una red de sentido que no posee una estructura de cohesión social fuerte entre el conjunto de quienes forman parte de la red. Las redes simbólicas son procesos de inter-reconocimiento entre los miembros de la red. En este caso encontramos movimientos como los punks, los funkies, los raperos estadounidenses y brasileños, o algunos grupos grafiteros, donde los jóvenes se saben parte de una red juvenil, se reconocen en la música, comparten situaciones lúdicas, se encuentran en los bailes y muchos de ellos son activos creadores de canciones, textos o espacios, donde dan cuenta de su situación en cuanto jóvenes pobres.

Entre las modalidades de disidencia y de resistencia en el ámbito estético / artístico, existen sectores y grupos estigmatizados, para quienes la fuerza del estigma muchas veces conlleva la posibilidad de conformar procesos apropiados de identificación a pesar de las respuestas de la sociedad global y de sus grupos dominantes; en ese sentido, podemos recurrir a la noción de "identidades proscritas" denominadas por José Manuel Valenzuela (2008: 45) como

... aquellas formas de identificación rechazadas por los sectores dominantes, donde los miembros de los grupos o las redes simbólicas proscritas son objeto de caracterizaciones peyorativas y muchas veces persecutorias. Entre estas encontramos desde agrupaciones políticas con posiciones ideológicas contrarias a los sistemas dominantes, grupos étnicos, grupos con adicción a las drogas, grupos religiosos, grupos nudistas, o algunos grupos o redes juveniles, como ha sido el caso de los beatniks, los pachucos, los hippies, los cholos, los punks, los chavos banda, los funkies".

\section{- Colectivos Hip-hop}

En Medellín se resaltan las "acciones colectivas" realizadas de forma puntual y significativa por grupos artísticos, que tejen la relación entre música y resistencia social y política, y en la investigación de Prácticas de participación política juvenil desde las cuales los y las jóvenes construyen ciudadanías en la ciudad de Medellín se reconoce la fuerza aglutinadora del hip-hop, al congregar a múltiples grupos juveniles en barrios y comunas, con un significativo nivel de gestión en los espacios de presupuesto participativo juvenil, logrando en cada una de las zonas de la ciudad Medellín, permanecer y posicionar su propuesta de participación política desde la estética, con el fortalecimiento de grupos de break dance, rap y graffiti. En el movimiento hip-hop de Medellín, se resalta la importancia de la estética como elemento articulador de la propuesta hip-hop presente en la ciudad de Medellín; una estética que involucra el cuerpo, el canto, la pintura y la música, al convertirse en los elementos artísticos y culturales vigentes en el hip-hop.

\section{CONCLUSIONES}

El rastreo de los antecedentes teóricos y un primer acercamiento a las prácticas de participación juvenil -a partir del diálogo con quienes, de distintas maneras, hacen parte de ellas- en la ciudad de Medellín nos permiten esgrimir las siguientes conclusiones. 
- Cualquier indagación seria acerca de la participación política juvenil compromete decididamente la pregunta por la condición juvenil en cada momento histórico y en cada contexto social. Esta consideración aparece como el producto de un consenso entre los investigadores del tema de participación juvenil y se sustenta en la idea de que en muchas ocasiones juzgamos las actitudes o las actuaciones juveniles a partir de una imagen cargada de añoranza de lo que significaba ser joven en otro momento histórico.

- En los y las jóvenes los referentes que los congregan están más cerca del arte, la música, la cultura, el deporte y, en general, del universo sensible que de los "grandes ideales de transformación social". Estos referentes no solo operan como ejes medulares en la construcción de la identidad juvenil, lo que ya es un hecho político, sino que, a nuestro entender, presentan una dimensión política en distintos sentidos: el primero porque apuntan a la visibilidad del sujeto joven y la búsqueda de reconocimiento y legitimación social de sus prácticas; el segundo porque entran en la escena del "mercado político" para lograr que sus proyectos sean considerados en los presupuestos oficiales. El tercero porque toman distancia o incluso se convierten en grandes cuestionadores (desde la disidencia o la resistencia) de las prácticas políticas hegemónicas.

- Los jóvenes son más sensibles que cualquier otro grupo etario a los discursos y a las prácticas que abogan por la diversidad, la inclusión y el cuidado del medio ambiente y los derechos humanos; tal vez sea esta la razón que explique la acogida que tienen ciertos proyectos políticos que acuden a estos referentes.

- Los y las jóvenes son más proclives a luchar por las "pequeñas causas" y por los asuntos cercanos a su cotidianidad, que a hacerlo por proyectos o por ideales cuyo alcance sea a largo plazo. Esta condición puede encontrar su explicación en el carácter efímero, flexible y discontinuo que exhiben las organizaciones juveniles.

- En coherencia con las ámbitos y escenarios de participación política juvenil presentadas en este artículo, es pertinente asumir una noción de participación constituida no sólo por los modos legitimados de participar sino por lo que los y las jóvenes en sus formas de agrupación consideran. De aquí que se debe profundizar en: 1) la relación de los jóvenes con los modos legitimados de participar entendiendo esto no sólo como las instituciones clásicas (ej. partidos políticos) sino también con los modos en que se considera "adecuado" participar en ellos (ej. acuerdos de convivencia escolar); 2) las prácticas de participación que los y las jóvenes consideran como tales (ej. marchas de protesta, tomas de espacio público, conciertos, conmemoraciones sociales y culturales, acciones directas); 3) los colectivos juveniles asociados a focos críticos de la sociedad (ley del aborto, clínica de la mujer; desconectados de servicios públicos, seguridad ciudadana y conflicto armado en las comunas) y 4) los modos de participar que los y las jóvenes crean o reconstruyen en la vida cotidiana (ejemplo: escuelas de Hip Hop, grupos artísticos, colectivos de mujeres contra las violencias y agresiones al cuerpo de la mujer). 


\section{REFERENCIAS BIBLIOGRÁFICAS}

Abad, M. (2002). Posibilidades y limitaciones de la participación juvenil para el impacto en la agenda pública. El caso del Consejo Municipal de Juventud de Medellín. Revista Última Década. No. 17. Villa del Mar, Chile.

Arias Barrero, L. (2004) Organización y participación social en Colombia. Fundación Universitaria Monserrate.

Garcés, Á. (2006) Juventud-signo. Revista Unirevista. No. 2. Brasil.

Giraldo, M.; Hoyos, G. y Zapata, C. (1997). Sistematización de una Experiencia de Participación Política Juvenil: el CMJ de Medellín. Medellín: [s.n].

Sánchez, J. (2008) ¿Existen verdaderamente los derechos políticos? Revista Universidad del Quindío. Vol. 1, No. 6. Armenia, Quindío. Colombia. pp. 5-17.

Valenzuela Arce, J. (2008). Identidades y agrupamientos juveniles. En: Garcés Montoya, A. (2008). Investigación en comunicación: Vigencia y prospectiva. Juventud, identidad y comunicación. Sello Editorial Universidad de Medellín.

Valenzuela Fuentes, K. (2007) Colectivos juveniles: ¿inmadurez política o afirmación de otras políticas posibles? En: Revista Última Década. No. 26. Cidpa, Valparaíso.

Zarzuri Cortes, R. (2008). Jóvenes, participación y movimientos sociales: hacia la construcción de nuevas formas de participación juvenil". Centro de Estudios socio-culturales, Chile. http://www.cesc.cl/pdf/centrodedocumentacion.pdf (consultado 1 octubre, 2008).

Zemelman, H. (1992) Horizontes de la razón I y II. Dialéctica y Apropiación del presente. El Colegio de México. Ed. Anthropos, España.

Zemelman, H. (1998) De la historia a la política: la experiencia de América Latina. México: Siglo Veintiuno editores.

Zemelman, H. (1998) El conocimiento como desafío posible. Colección: Conversaciones didácticas. EDUCO. Universidad del Comahue, Argentina. $2^{a}$ Edición UPN Pachuca, México. Hugo Castellanos Editores.

Zemelman, H. (1998) Sujeto: existencia y potencia. España: Anthropos. 